\title{
INTERACTIVE EXPLORATORY OBJECTS: FROM LABORATORY EXPERIMENTS TO MASS PRACTICES OF THE XXI CENTURY
}

\author{
A.N. PODDIAKOV ${ }^{\mathrm{a}, \mathrm{b}}$, N.N. PODDIAKOV
}

\begin{abstract}
${ }^{a}$ National Research University Higher School of Economics, 20 Myasnitskaya Str., Moscow, 101000, Russian Federation

${ }^{b}$ Institute of Psychology, Russian Academy of Sciences, 13 build. 1, Yaroslavskaya Str., Moscow, 129366, Russian Federation
\end{abstract}

\begin{abstract}
The paper is focused on the history and modern practices of creating and applying interactive exploratory objects and worlds that provoke curiosity in the individual and require exploration and experimentation to learn them and to achieve practical goals. The development, use and demonstration of a wide range of exploratory objects (play, educational, psycho-diagnostic, etc.) in various fields reflects an increasingly wide spread belief: one of the basic human abilities that is needed now and will be in demand in the future is the ability to cope with novelty, including through active exploration and experimentation. Five interrelated directions for the development and popularization of exploratory objects are identified: science; educational practice; assessment; game practices; and literature, art, official and unofficial journalism. Parameters of specially developed interactive exploratory objects and worlds in the context of preparing for encounters with novelty and complexity are discussed. The triangle of tests of intelligence, creativity and exploratory behavior in the space of regulation - freedom is presented. Two types of motivational challenges when exploring new objects are described: exploration for the sake of the very process of cognition and exploration for the sake of desired practical effects. The issue of features of exploratory objects that stimulate posing and solving epistemic problems rather than pragmatic problems, and vice versa, is raised. In conclusion, possible reasons for the mass development and supply of exploratory objects and worlds are formulated.
\end{abstract}

Keywords: interactive exploratory objects, experimentation, exploratory behavior, intelligence, creativity, education, games.

At present, there is a great interest in culture in the study of novelty - novel objects, situations, and worlds. There are films emerging where the protagonist is an astronaut on a different planet alone fighting for survival, and one of the ways to struggle for life is the exploration of the external environment and the possibilities of materials, tools and instruments brought from Earth and their creative use. Varieties of quests are extremely popular with both adolescents and adults who pay

This paper was prepared with the support from the Russian Science Foundation, Grant \# 17-78-30035. 
money, for example, to be locked alone or in a small group in a room with various incomprehensible objects, stashes, ciphers, etc., to solve all mysteries and get out during a set period of time.

The number of toys for children is intensively growing that function to develop the child's thinking during exploration and experimentation (this is what is explicitly written in the instructions). These are a special class of toys (they are neither dolls, nor little cars, nor little cups and saucers, etc.). They do not have a clearly identified practical function, but they look like diverse attractive little boxes with buttons, windows, light panels, hidden speakers, moving elements, etc. When the child presses a button or turns a handle, a window is lit and a funny image appears; when another button is pressed a nice whistle sounds; when you press the third button, a niche opens and there is something interesting inside that was not visible before, etc. In terms of cybernetics, such toys are 'black boxes' with unknown content, and now they are en masse offered to preschoolers for instructionless exploration and learning.

Computer games that imply exploration, experimentation and problem-solving are quite popular: those are advanced adventure games for amateurs, and less complex investigational logic puzzles offered immediately to a huge number of Internet users. Some interactive Google Doodles can be an important and illustrative example of such games created for a worldwide audience. Considering the significance of the received response, we should start with Google Doodle that was dedicated to the 60th anniversary of Stanislaw Lem's first publication'. It is hardly possible to name another writer (a sci-fi author and a philosopher) who has equally contributed to the explanation and popularization of the topic of exploring various black boxes of natural and artificial origin, like Lem. Accordingly, Google users were offered to experiment with amusing black boxes of increasing complexity, and this Google Doodle became the subject of publication in the Daily Mail, The Guardian, The Telegraph ${ }^{2}$, etc. It is also worth mentioning the recent Google Doodle, which requires experimenting with the range of catapult throws of garden gnomes figurines; the properties of their flight are initially not obvious ${ }^{3}$; etc. In all these Google Doodles the user is not given any instructions - they must understand on their own, through exploration and experimentation, the way virtual objects work.

Moreover, experimenting with a new technical object (device) without preliminary briefing ("Just experiment and see how it works") becomes an important aspect of mass diagnostics of 21st century skills. We can use as an example interactive items designed for the Program for International Student Assessment (PISA).

\footnotetext{
${ }^{1}$ https://www.google.com/doodles/60th-anniversary-of-stanislaw-lems-first-publication

${ }^{2}$ http://www.dailymail.co.uk/sciencetech/article-2065103/Stanislaw-Lem-Google-DoodleI n t e r a c tive - a n i mation-celebrates-s c i-fi-gen i u s-work. htm l https://www.theguardian.com/technology/2011/nov/23/google-doodle-stanislaw-lem-anniversary, https://www.telegraph.co.uk/technology/google/google-doodle/8908900/Stanislaw-Lem-60thanniversary-of-first-book-celebrated-with-giant-robot-Google-Doodle.html

${ }^{3}$ https://www.google.com/doodles/celebrating-garden-gnomes?hl=en
} 
The Program involves hundreds of thousands of 15-16-year-old schoolchildren from dozens of countries. In 2012, for the first time in the history of mass testing and evaluation, the participants proposed a new type of tasks (for international mass testing rather than for scientific psychology or for Google users) - interactive assignments. For example, while clicking on the buttons of a virtual MP3 player (that doesn't have a manual provided) and observing the reactions, the participant had to understand the operating principle and then perform tasks that assess understanding of this principle (OECD, 2013, 2017). Another task of the same type is called Climate Control (experimenting with another device - air conditioning $)^{4}$. Directions to assignments of this type often paradoxically begin with the words: "You have no instructions for your new device. You need to figure out how it works (how to use it)."

The explicit or implicit premise ("there are no instructions for the new object so it needs to be explored") seems to be a philosophically loaded feature and the key characteristic for the development of all the above examples, rather than numerous problem-solving situations created by some people for others. The main component of these situations is the presence of exploratory objects (or whole worlds) that are designed on the principle of black boxes of varying complexity and blackness (opacity) - they need to be explored and experimented with, their non-obvious, hidden properties are to be identified, and connections for their understanding and the successful achievement of those or other purposes should be located. In a sense, given the growing scale, this is a new civilizational situation.

In general, at least five interrelated directions for developing exploratory objects can be identified.

1. Science - the exploration of the means by which different people (children, adults, beginners, experts, etc.) cope with novel objects and (micro) worlds, their motivations, cognitive strategies used, the effect of different features of these objects on motivation, the parameters of strategies, etc.

2. Educational practice - the inclusion of exploratory objects and worlds in learning and development programs.

3. Evaluation - an assessment of the degree the assessed people have competence in exploring novel objects and worlds.

4. Game practice - the development and production of exploratory toys for children and adventure games with a pronounced research component for people of all ages (if only they were interested).

5. Literature, art, official and unofficial journalism - here exploratory objects and worlds are represented as 'human displays' in the understanding introduced by Gibson (1979, p. 42). Human displays are sculptures, paintings, photographs, films and animated cartoons, written texts, etc. Being specially created for other people all these objects, "mediate or indirect, knowledge at second hand" (Ibid.). For our part, we will give examples of specially created 'human displays' that represent for other people mediated or indirect knowledge about exploration, experimentation, their possible objects, predictable and unpredictable effects. Those include:

\footnotetext{
${ }^{4}$ http://www.oecd.org/pisa/test-2012/testquestions/question3/
} 
- a scene in a science fiction feature film of an astronaut experimenting with an artifact from another civilization on another planet;

- a scene in the animated film by Zdeněk Miler of the Little Mole experimenting with a radio receiver (the character had never seen radios before);

- a description of the young Moomins experiment with the Magician's Hat (that was black, of course, like the 'black box') in the fairy tale of the same name by Tove Jansson;

- a description in an Internet publication of a person who tried to work out the mechanism of a tap or an air conditioner of an unknown model in a hotel abroad;

- Youtube videos posted for mass viewing that show how children react to a jack-in-the-box ${ }^{5}$, etc.

We are talking about the relationship of these five aspects that can be most easily explained in the above example of Google Doodle dedicated to the 60th anniversary of Stanislaw Lem's first publication. Lem's written texts (the Cyberiad cycle) became an incentive for the Google computer company to create an interactive computer toy, which in turn works as a source of direct exploratory experience for the player and a source of observation for her or his younger sibling or a desk mate at school; it may be a topic for discussion in private Internet blogs and the subject of reports in the Daily Mail, The Guardian, The Telegraph, etc., as well as an example of a research object in the paper you are reading. However, as will be shown below, the network of interconnections between aspects of the development of exploratory objects is not limited to this example - it is much broader.

\section{A brief history of the development of exploratory objects}

In human culture, puzzles - toys that can be understood through experimentation, have been known for a long time: at least since the Middle Ages. These are different puzzle boxes that cannot be opened if you don't know the secret; puzzle mugs with hidden holes and canals inside the walls designed not so much for drinking as for pouring the liquid all over the drinker (if they cannot figure out by researching how to hold it and which holes to press their fingers against).

Scientific research and diagnostics of exploratory behavior with the help of specially designed objects began in the second half of the 20th century. Although the history of the study of exploratory behavior begins with the work of I. P. Pavlov on orienting reflexes and orienting-exploratory reactions, afterwards, until the 1950s, the studies mainly focused on the reactivity of animals and humans. Often they were conducted using Skinner boxes in which the animal had to find an operational means by using a key or bar in order to get food or other reinforcement. The value of one's own free cognitive activity guided by curiosity and manifested in independent

\footnotetext{
${ }^{5}$ https://www.youtube.com/watch?v=WWxUkzOJX58. Different versions of the jack-in-thebox (toys designed to have an object unexpectedly jumping out that is (un)attractive, for example, a little devil, during the investigation) can act not only as exploratory objects, but also as counterexploratory objects; see in (Poddiakov A., 2017) on this opposition.
} 
exploratory behavior was realized and recognized later. If behaviorists were rather interested in reactivity (the stimulus-response scheme), the new paradigm opposed this, for it became a paradigm of free activity, including exploration, in a complex environment.

In this paradigm, the ideal of an experimental object (offered to the participant to perform independent cognitive activity) is an object with an infinitely large number of different-level hidden elements, properties and connections - from those that can be easily identified and are almost obvious, to those extremely difficult to detect and understand. At the extremes of activity modeled in such an experiment is the intrinsically motivated cognition by a subject of a complex, diverse world that gradually unfolds at emerging levels (Poddiakov A., 2012). The person here (unlike demonstrating reactions with the Skinner box) can set increasingly complex epistemic and practical goals and apply different strategies. Accounting for the diversity of goals and strategies is a fundamental feature of the study of curiosity and exploratory behavior, in contrast to the study of behavior based on Skinner boxes, where the learning curve is always assumed to be fundamentally the same not only for different individuals, but for different species (it may differ only in the degree of steepness-flatness).

Participants in the experiments on studying curiosity and exploration are offered specific specially designed exploratory objects and environments of varying complexity that allow the realization of the principle of the developing cognitive intrigue and thereby induce the participant to actively forecast, hypothesise, explore and experiment (Poddiakov N., 2011, 2012).

As an example of an exploratory object (which was new and rather complex for children) used in psychological experiments in the late 1950s, we should describe a device developed by one of the authors of this paper, N. Poddiakov, who at that time was a post-graduate student of A. Zaporozhets. (In the 1920s-30s, Alexander Zaporozhets was a student and colleague of Lev Vygotsky, and in the 1950s he organized his own direction in studying the research activities of children.)

The experiments of $\mathrm{N}$. Poddiakov became one of the first (or, probably, the first) research where preschool children were offered to independently explore new objects with rather complex hidden connections that required detailed experimentation (Poddiakov N., 1959, 1960, 1977; Poddjakow, 1981). (We will be grateful if earlier analogues could be indicated; the study of the children' orienting activity aimed at the establishment of connections between buttons and bulbs that would light on a stand, had different versions before, but it seems that there has been no studies of experimentation and searching for ways to remotely control a new dynamic object). For example, a child of 5 y. o. was offered an object with four buttons that controlled the movement of a doll (a toy boy) on the working field (Figure 1). When one or another of the four buttons were pressed, the doll could move in one of four directions - to the participant (who was behind the control panel), away from the participant, to the right and to the left. By alternately pressing the buttons of the remote control, it was possible to bring the doll to any point of the experimental field, and to make it circle it around any obstacle placed in its path. By experimenting with the buttons (they did not have any information on 
The device for study of children's experimentation (Poddiakov N., 1977; Poddjakow, 1981)

- - buttons that have originally unknown functions

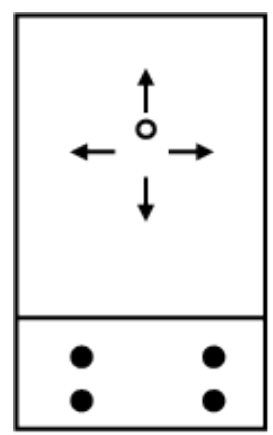

them) the child had to understand how the device worked, how to guide the boy through the labyrinth of various complexity, etc.

Now, in an era when practically every household device is equipped with buttons with arrows $\leftarrow, \rightarrow, \uparrow, \downarrow$, this exploratory object and the principle of controlling it seem simple, but in the 1950s, when it had been developed and applied in psychological experimentation, these types of remotely controlled toys were a much rarer phenomenon than now, and did not seem to be used at all in psychological experiments to study the exploratory behavior and thinking of preschool children. In order to have an approximate understanding of the nature of the preschooler's activity in the 1950s who would sit behind this experimental setup, you may imagine that you have a remote control for a vacuum cleaner without any signs on the buttons. Besides, you do not know what a vacuum cleaner is. Perhaps during the survey of this object you will have a normative idea formed of the object and its function, but perhaps you will find another (unexpected and creative) use for it.

A number of experimental schemas for studying thinking using such objects were also designed (Poddiakov N., 1977; Poddjakow, 1981). First of all, they include, for example, alterations in the structure of hidden links that a child wouldn't expect in an object that they seem to have already studied: the buttons of an object changed their functions at some point - functions of a button would be performed by another one (for example, the button that moved the doll to the left, would begin to move it forward; the button that used to move it forward would have changed to moving the doll to the right, etc.). This caused astonishment in children and new cycles of experimentation with a seemingly well-known, identically looking, but inwardly substantially changed, 'reprogrammed' object that could not be controlled then in the same way as the child had learnt before, and it was necessary to understand what to do then. In the late 1950s with the use of this object important differences were found in the child's experimenting exploratory actions aimed at establishing causal links in the object: from the performance aimed at directly solving a practical task (for example, to direct the doll to go between the placed barriers from one end of the field to the other). The readiness of children for 
transitions from direct experiment to experiment when the button functions changed (in a 'turbulence mode' of the object and activity) and back (from experiment to direct experiment and even automated acts) when the 'updated', reset button functions were fully understood by the participant, and the need for the samples would disappear (in a 'stability mode').

In the 1960s the number of exploratory objects invented by researchers and used in experiments was growing as was the diversity of the goals of these experiments. Keller gives images of some exploratory objects for children of different ages (Keller, 1994). First of all, this is a Hutt-box (for children from 2 years old), perhaps, at some point it was one of the most famous exploratory objects. It was developed by C. Hutt and enabled the operationalization of the differences between the specific and diversive exploration in Berlyne's terms, or between exploration and play in Hutt's terms (Hutt \& Bhavnani, 1972). The very sequence of images of these objects shows some aspects of their complication to match the age characteristics of the participants.

At present, one of essential trends (in terms of the transition from laboratory experiments to mass practices) is the development of exploratory objects that can be understood not only by children (if the participants are children) but also by parents in terms of the functions of these objects in the cognitive development of children, and which additionally stimulate parents to independently examine and develop their children's exploration and play, to find new exploratory objects for their children, etc. One example is what the Discovery Center's Living Laboratory offers to the visitors of the Museum of Science (Boston, USA) ${ }^{6}$. Developmental psychologists from different scientific centers cooperate with the laboratory. One of the important directions here is the study and popularization of learning through play ${ }^{7}$. At the Living Laboratory website parents can read short understandable notes 'How does expectation affect exploration?', 'Do children prefer to explore toys that provide clear evidence?', 'Do children play more when evidence is not clear?', etc. After reading the description of a scientific experiment where children experiment with an interesting exploratory toy, and having seen the attractive images, parents also read the suggestions and invitations: "Find a toy in your home that has many buttons or levers that your child can investigate. Does your child take time to push one button or lever down at a time to find out how it works? How long will your child play with one toy before moving on to a new one?"10, etc. This is one of the manifestations of the transition from laboratory experiments to mass practices. Any parent on the planet who uses the Internet, after reading these descriptions and invitations, can take an exploratory position in relation to exploratory behavior and experiment with exploratory objects of their child.

\footnotetext{
${ }^{6}$ https://www.mos.org/living-laboratory, http://legacy.mos.org/discoverycenter/livinglab

${ }^{7}$ http://legacy.mos.org/discoverycenter/livinglab/ltp/list

${ }^{8}$ http://legacy.mos.org/discoverycenter/livinglab/ltp/phonesthemes

${ }^{9}$ http://legacy.mos.org/discoverycenter/livinglab/ltp/popbeads

${ }^{10}$ https://www.mos.org/living-laboratory/explore-our-research/jack-in-the-box
} 
Another example of the popularization is that developers of interactive tasks for PISA 2012 (that are offered to tens of thousands of schoolchildren and require exploration and experimentation with new objects), indicate that these tasks are based on the complex problem solving approach (OECD, 2013, 2017). In the 1970s the approach was launched with the laboratory experiments of D. Dörner (1997). We can also make an informed assumption that the Tanaland, Moro, and Lohhausen scenarios developed then by Dörner for laboratory research of thinking, were the forerunner of many modern strategic computer games such as SimCity, Civilization, etc. (Poddiakov A., 2012; Riegler, 1998).

Throughout the history of scientific studies of curiosity and exploration, the developers have created exploratory objects and worlds to identify psychological phenomena and patterns in two related areas - motivation and cognitive strategies (e.g., strategies of causal inferences) (Bonawitz et al., 2011; Buchsbaum, Gopnik, Griffiths, \& Shafto, 2011; Chase \& Klahr, 2017; Cook, Goodman, \& Schulz, 2011; Dean \& Kuhn, 2007; Dörner \& Funke, 2017; Ford, 2005; Forman, 1986; Funke, 2014; Greiff, Molnár, Martin, Zimmermann, \& Csapy, 2018; Jirout \& Klahr, 2012; Klahr \& Dunbar, 1988; Poddiakov A., 1992, 2011; Poddiakov N., 1959, 2011, 2012; Schauble, 1990; Schulz \& Bonawitz, 2007).

Computer technology plays an increasingly important role here. In the mid1980s experiments had been started where children and adults were asked to experiment with robots, computerized systems such as LEGO and computer microworlds; besides, computerized exploratory objects and worlds came into use in teaching scientific inquiry. An important modern trend associated with the development of technology is the development of virtual exploratory objects and worlds that allow:

- the creation of computerized interactive collaborative problems for collaborative exploratory activities of several participants based on the principle of jigsaw problem: none of the participants have complete information about the task and a sufficient set of solutions; the information and material resources of all participants vary, and the research task can be solved only by negotiating, exchanging information, and combining the possibilities (Graesser, Kuo, \& Liao, 2017; OECD, 2013, 2017);

- the collection of big data and use of data mining on the research strategies of a large number of users (Greiff, Niepel, Scherer, \& Martin, 2016);

- the study of a participant's brain activity during the survey of new worlds and the relevant objects (certainly so far on small samples in laboratory settings) (Fields, 2016; Snider, Plank, Lynch, Halgren, \& Poizner, 2013).

\section{Tests of intelligence, creativity and exploratory behavior in the space of regulation - freedom}

It is probably no coincidence that in the same historical period (1950-60s), the animated film The Mole and the Car by Zdeněk Miler was shot (where one of the key episodes is how the Little Mole examines a parking lot and a car), and Tove Jansson wrote The Exploits of Moominpappa (Moominpappa's memoirs) where 
there is a wonderful piece about Daddy Jones's garden, a specially created exploratory, adventure environment where characters explore and find something at their own will and understanding, and then, unexpectedly for them, according to the results of these searches, they are rewarded and receive information about their individual characteristics (!). And it is no coincidence that at that time the first scientific psychological studies of independent exploratory behavior began to unfold opposing the behaviorist study of behavior in Skinner boxes. The period of the 1950-60s was a new socio-cultural situation, and the concepts of novelty and freedom, and free choice in a new environment should be used as key concepts to describe it. (The new youth movements of the 1960s, hippies, rock music, the movement of radio amateurs who would invent the first and so far unprecedented electronic video games, etc., etc., can also largely be described by these concepts.)

We shall turn to the tests. Such freedom, as in the tests of exploratory behavior, had not always been provided to participants, but also became a reality from the 1950-60s.

Historically, the first tests of intelligence appeared at the turn of the 19-20 centuries. They measure a person's ability to quickly solve a large number of problems from a proposed set during a limited time. The tasks are already clearly formulated by someone, they have a known way of solving and the answer, which is considered to be the only correct one. In the 1930s tests of a new type were developed to overcome the one-sidedness of intelligence tests - tests of creativity. They use openended tasks, that is, they have not one single right answer, but presuppose the possibility of multiple answers (in the limit, infinite).

These tasks are designed to induce a person to invent new, diverse, original solutions to the problem posed by another person (developer). For example, you need to come up with as many ways of unusual use of the seemingly most common object (like a pencil, a brick, etc.), to invent as many improvements as possible of a toy, etc. Tests of exploratory behavior emerged in the 1960s that allowed the study of aspects of cognitive activity that were not covered by tests of intelligence/creativity. Tests of exploratory behavior diagnose a person's ability to acquire new information in real interaction with new unknown objects, to act practically in conditions of novelty and uncertainty, while independently setting and solving various exploratory (inquiry) tasks.

We shall emphasize this fundamentally important aspect. Although problem posing is considered an important part of learning and thinking in some educational approaches (Brown \& Walter, 2004; Mishra \& Iyer, 2015), it is difficult to find psycho-diagnostic tests that would assess a person's ability to pose problems and come up with tasks, rather than just to solve problems posed by someone else. Tests of exploratory behavior provide such an opportunity.

The most universal tests of exploratory behavior can be described as problematic situations that have both an open end and an open beginning. The open beginning means that here (in contrast to the tests of intelligence and creativity tests) the participant themselves poses problems and "asks questions" to the object, poses tasks and solves them, constantly collecting and defining information about all emerging properties of the object and conditions of achieving the goals. Tests of 
exploratory behavior enable both the freedom of answers and the freedom of questions. On the one hand, this is the freedom of questions to the object or the system (What are you, what is the way you are arranged, how will you react if I do this? And what if I do that?, etc.). On the other hand, these are new degrees of freedom that are related to other people's questions: questions to the experimenter, as well as questions to joint survey partners when it comes to the interactive collaborative problem situation: What do you see? How did the object react when I did this? What can we think of in order to learn this better?, etc.

Does this mean that, for example, there is absolutely no freedom in intelligence tests? There is freedom, the freedom to find a solution that was conceived by the developer and is unknown to the subject. But there is no freedom for an independent statement of a problem or a question.

Accordingly, we can offer a 'triangle of types of test problems.' This is a graphic model of the relationship between the tasks of tests of intelligence, creativity and exploratory behavior and various real problems in the space of regulation - freedom (Figures 2, 3).

We should understand that although tests of exploratory behavior increase degrees of freedom, freedom is not as ultimate as in creativity tests, where the flight of imagination can be almost unrestrained (you can finish a proposed figure as you like, just be original, different from other participants). And when a real object is explored, physical limitations of the real world come into play. Some things in the real world cannot be done (for example, clearly you cannot make a perpetual motion machine and a research instrument based on it). Therefore, in the proposed triangle of tests, the freedom of answers in tests of exploratory behavior is lower than in tests of creativity, although higher than in intelligence tests.

Inside this triangle of tests various cognitive tasks can be placed that exist in real life, according to the extent to which they are loaded with an exploratory component

The triangle of tests of intelligence, creativity and exploratory behavior in the space of regulation - freedom

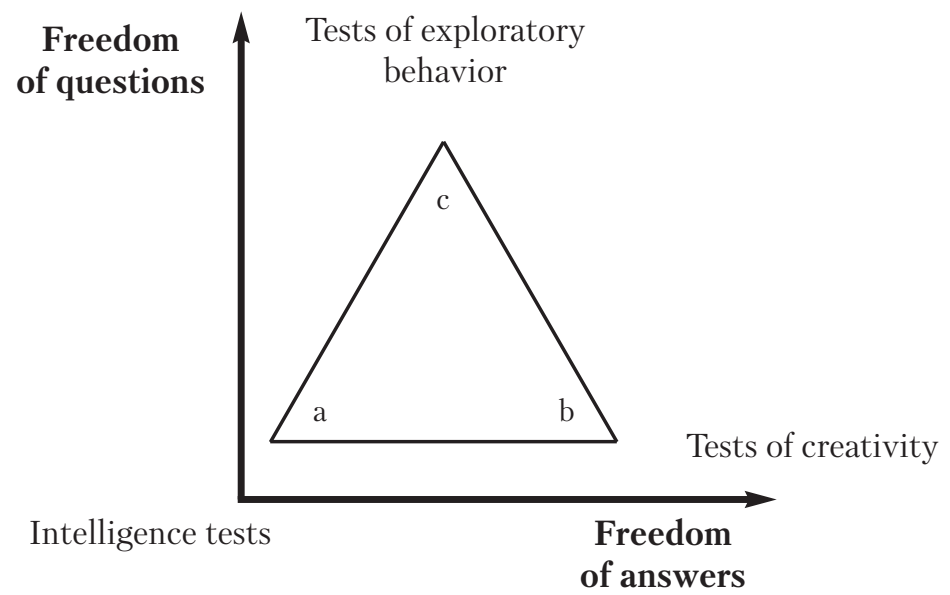


The variety of real problems in the contour of the 'triangle of tests' of intelligence, creativity and exploratory behavior

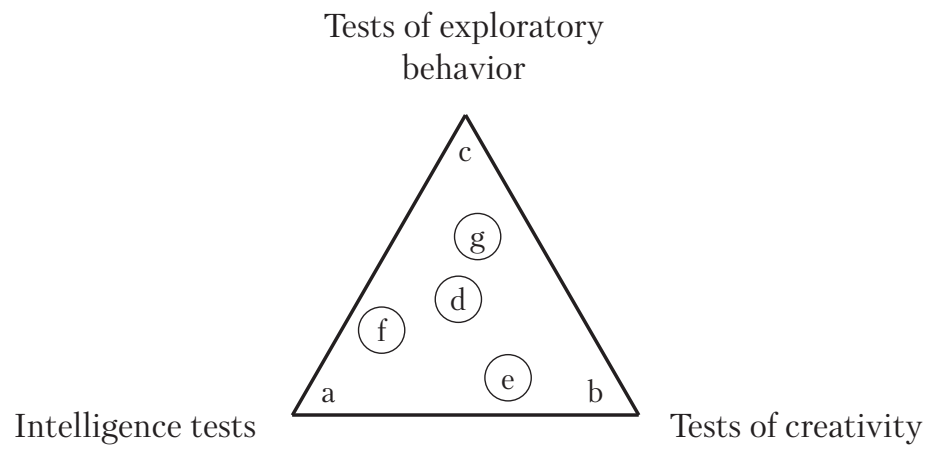

a - tasks that predominantly require intelligence as it is understood in tests;

$\mathrm{b}$ - tasks that predominantly require creativity as it is understood in tests;

c - tasks that predominantly require exploratory behavior as it is understood in tests;

$\mathrm{d}$ - mixed tasks that require both exploratory behavior, creativity and intelligence in an approximately equal proportion;

$\mathrm{e}$ - mixed tasks that predominantly require creativity and intelligence and to a lesser extent, exploratory behavior;

$\mathrm{f}$ - mixed tasks that predominantly require intelligence, less exploratory behavior and, to an even lesser extent, creativity;

$\mathrm{g}$ - mixed tasks that predominantly require exploratory behavior and, to a lesser extent, creativity and intelligence as they are understood in tests.

(the potential and the need to observe and practically experiment with objects and systems while getting emerging information about their properties, connections, etc.), a creative component (the ability and necessity to generate multiple original solutions) and an intelligent component in the test sense (the necessity to seek accurate answers to questions clearly posed by someone). Such a triangle, without claiming to provide an exhaustive picture of cognitive activity, enables the evaluation of certain real life and professional cognitive tasks in regard to the proportion of various important components in them (Figure 3).

Thus, throughout the 20th century, a trend in the development of testing cognitive abilities can be seen that stretches from the maximum regulation of the subjects' activity (when solving tasks clearly formulated by the developer that have the only correct answer) to diagnostic problematic situations of high novelty and uncertainty that have open beginnings and open ends and imply the use of special exploratory objects and worlds to design and develop them. And these exploratory objects and worlds are of great interest. This is natural. After all, the developer's task is to create an exploratory object that is meta-affordance, an opportunity 
offered to another person to satisfy their cognitive motivation and motivation in the new system (Poddiakov A., 2017). Let us focus here again on IQ tests. Their developers in the beginning of the 20th century did not aim to make the tasks interesting for the participant (they could be interesting for some participants, but not due to the specially set goal of the developer, but rather due to the individual characteristics of certain participants). With the tests of creativity and, especially, of exploratory behavior, the situation is different as the participants' cognitive interest is of importance here, so that they could take advantage of the freedom they are given; the need to develop the participant's personal cognitive interest is taken into account when developing test objects. If a participant is not interested in a task in an IQ test, this does not really bother the test developer. If the participant is not interested in a task of a creative thinking test or a test of curiosity and exploratory behavior, we call it a professional failure of the developer.

\section{Two types of challenges when exploring new objects}

When a person explores new objects, two types of challenges can be identified that affect the specifics of cognitive strategies. One of the challenges is to understand a new and complex object as such, irrelevant to possible utilitarian and practical results. Here cognitive strategies are directed by curiosity and the need to obtain new information and new knowledge. Getting knowledge here is 'disinterested,' it happens for the sake of the very process of cognition (Poddiakov N., 1977; Poddjakow, 1981).

The other type of challenge is to make the new and complex object function in the desired way, to elicit from it the necessary practical effects (for example, to force a new device to work in a desired mode). This is possible only on the basis of the preliminary examination and understanding the object, but here other cognitive strategies for the problem of posing and problem solving are deployed (Ibid.). The real process of cognition is maintained in the close interaction of both types, and depending on the prevalence of one or the other type of challenges, the entire thinking process as a whole acquires a relevant tendency.

A similar distinction was introduced by Schauble (Schauble, Klopfer, \& Raghavan, 1991). The researchers write that students can implement in their exploratory activities either scientific or engineering models of experimentation, that is, they either seek to understand the internal cause-effect relationships within the object, or try to obtain from it a certain desirable practical outcome (for example, the maximum speed of a new virtual car). This difference in goals leads to varied research strategies and a focus on different sides of the object.

The authors point out that the difficulties in teaching the basics of scientific inquiry to students are associated not only with the way children construct logical reasoning, but also with the fact that they often confuse the purpose of scientific experimentation with the one of the engineering model. The engineering purpose is quite appropriate, but it interferes with understanding the object in its completeness and variety of cause-effect relationships, which is not very good when teaching scientific inquiry. It is important that students should understand the differences between these goals. 
Can these or other exploratory objects intrinsically instigate a more rather disinterested exploration and experimentation motivated only by curiosity, than pragmatic research related to practical problems, and vice versa: can various exploratory objects provoke in relation to themselves more pragmatic exploration and experimentation, rather than unselfish, non-utilitarian study?

In this respect the Henderson and Moore study is important where a distinction is made between free exploration and problem-solving exploration, as well as between novel perceptual toys and problem-solving toys. Free exploration of novel perceptual toys is not aimed at finding any certain correct solutions and actions. This is a study motivated only by curiosity. Problem-solving exploration of problem-solving toys is directed by a problem (for example, to get a doll out of a narrow box) (Henderson \& Moore, 1980). However, here there is no focus on possible differences in epistemic challenges and problems (problems posed and solved, for example, in the scientific type of exploration and experimentation) and practical challenges and problems (in the engineering type of exploration and experimentation). Given these differences, one can talk not just about problem-solving exploration, but about its two different types associated with the epistemic and practical problems posed and solved by a person examining a new object. The question remains open about objects that stimulate rather posing and solving epistemic problems than pragmatic problems, and vice versa. We certainly understand that there are no absolute types in reality, and setting goals when faced with a novel object depends on the context and individual characteristics of the individual, but it seems important to assess the possible contribution of the object features to the type of challenge it stimulates.

\section{The reasons for the mass development and supply of exploratory objects and worlds}

The mass practice of developing and offering to people newer and more diverse exploratory objects and worlds has at least four reasons (and they are interrelated).

1. The intensive development, use and demonstration of a variety of exploratory objects in various fields (research, education, testing and evaluation, games, literature, art, official and unofficial journalism) is a reflection of an increasingly popular belief that one of the basic abilities of the person that is necessary at the present time and will be in demand in the future, is the ability to cope with novelty, including through their active exploration and experimentation. It is assumed that people should be specially prepared to encounter novelty, so specially developed novel interactive exploratory objects and worlds can be an effective means of specific preparation and implicit learning.

2. A new technological situation at the household level: in recent decades, the share of new components in even the household environment has increased so much that each of us regularly becomes an explorer of some 'black boxes,' should it be a water tap or an electrical appliance in a hotel of a design we have not known before (and other numerous constantly updated gadgets and different types of household appliances). Often there is no user's manual to them, but if there is, it 
may cover not all necessary information, nor for all situations, and it is not always in the native language of a user.

Then the lacking knowledge has to be gained through all sorts of explorations and experimentation, by checking the functions of the controls (buttons, handles, etc.) in different combinations, by observing the varying modes of operation of the device, etc. (Moreover, quite a lot of users prefer to learn new devices specifically this way, by independent research, and they refer to manuals only in the last resort.) Only 100-200 years ago, there was simply no such mass exploratory activity at the household level, there were no relatively complex devices available to an individual, or, moreover, their constant updates, on a mass scale. Only 50-100 years ago did people start to get involved in experimenting with emerging objects of the environment and everyday life, and this became an important area of competence.

3. The role of science is growing, and the popularization of academic achievements in various fields (physics, chemistry, biology, neurosciences, etc.) is often designed as a narrative: people did not know about a phenomenon or did not understand its causes until a certain scientist thought about it, invented a tool and a method to investigate it, and used them to identify previously unknown, hidden essential properties and connections of the studied objects, and subsequently the world has changed (a disease disappeared, new technology emerged, etc.). This narrative of the history of scientific success can be strengthened by the addition of a brief but impressive history of previous failures (for example, the death of scientists during experiments as they did not understand either the essence of the phenomenon being studied, or some important details). Such narratives translate the idea of exploration of novelty as an important challenge that is both engaging and dangerous. This idea is harmoniously built into the growing number and variety of adventure games that attract by the opportunity of exploration, experimentation and serendipity of positive and negative results.

4. Targeted activity of the stakeholders (psychologists, educators, IT-visionaries, etc.) who believe their mission is the development of the exploratory potential in people and who develop new exploratory objects and worlds that show their importance. Originally, around the 1950-60s psychologists in different countries began to understand and formulate the value of exploratory behavior and experimentation with novel objects and to design suitable experimental objects to study them. It can be said that psychologists performed the experimentation of the 'second order': they experimented with the experimenting activity of children and adults while constructing new and more complex objects and systems, new conditions and procedures for their use, and based on the obtained data, they built their models and theories of cognitive activity.

Thanks to this experimentation with experimentation (continuing to the present), researchers get new facts and change their concepts of the laws of cognitive activity and its development, as well as ways to manage this development. Exploratory achievements in the field of these 'experiments with experimentation' are delivered to the public consciousness through a communication system. These 
are the websites of the Discovery Center's Living Laboratory in the Museum of Science and the publications of leading scientists on exploratory behavior in the journals Nature, Science, Scientific American, Scientific American Mind (Fields, 2016; Hutt \& Bhavnani, 1972; Gopnik, 2010, 2012; Klahr, Zimmerman, \& Jirout, 2011).

One of the key conditions for the proliferation of the development and supply of new and more diverse exploratory objects and worlds is again the development of technologies (first of all, computer technology and media). We shall remind about interactive Google Doodles that are available to users around the world and are covered in key global media. Other examples include the development of a virtual puzzle-box (or even a world model) by a programmer over a day (a week or a month) that is uploaded in the Internet and actively explored and discussed by users; the development of virtual scientific laboratories for schoolchildren by specialists in the field of education and IT; etc.

The community reacts to all this by changing the social order, supporting research and practical development of new diagnostic, didactic, gaming exploratory objects, worlds, and activities; the spiral of development is spinning even farther (Poddiakov A., 2012); in chemistry, this is called an autocatalytic process.

\section{Conclusion}

Preparing for an encounter with novelty and complexity is one of the main challenges within modern education, and the constant meetings with novelty and complexity are a challenge of modern life. The developmental effect of these encounters (educational and real life encounters in the broad sense of the word) can be expressed by a qualitative mathematical formula (Poddiakov A., 2014). It reflects the difference between the novelty and complexity of problems that a person (society, civilization) can set and solve before and after formal and informal events, educational processes, interactions that either stimulate or delay the development:

$$
E=N^{\prime} C^{\prime}-N C
$$

where $E$ is the developing effect of events and impacts, $N$ and $C$ are respectively, novelty and complexity of problems that a person (society, civilization) could set and solve before these events and interactions; $N^{\prime}$ and $C^{\prime}$ are respectively, the novelty and complexity of problems that a person (society, civilization) can pose and solve after these events and interactions.

An important means of preparing for meeting and working with novelty and complexity is the organization of collisions with specially designed exploratory objects and worlds. Will the mass development of these exploratory objects, worlds and activities continue to develop with an increasing speed, perhaps even more than now, or at some point (which is quite likely) will it slow down (like any mass trend) or even stop and go backwards? What could be the causes of this increasing acceleration, or, conversely, of inhibition and retreat? Developmental and cognitive 
psychologists who invent and design exploratory objects and worlds and read books by Stanislaw Lem, could think about it.

Incidentally, in addition to the actual cognitive interest, this can become the basis for an adventure game plot. Perhaps, in the beginning it will have to be tested in laboratory conditions.

\section{References}

Bonawitz, E., Shafto, P., Gweon, H., Goodman, N. D., Spelke, E., \& Schulz, L. (2011). The doubleedged sword of pedagogy: Instruction limits spontaneous exploration and discovery. Cognition, 120(3), 322-330. doi:10.1016/j.cognition.2010.10.001

Brown S. I., \& Walter, M. I. (2004). The art of problem posing (3rd ed.). New York: Routledge.

Buchsbaum, D., Gopnik, A., Griffiths, T. L., \& Shafto, P. (2011). Children's imitation of causal action sequences is influenced by statistical and pedagogical evidence. Cognition, 120(3), 331-340. doi:10.1016/j.cognition.2010.12.001

Chase, C. \& Klahr, D. (2017). Invention versus direct instruction: for some content, it's a tie. Journal of Science Education and Technology, 26(6), 582-596. doi:10.1007/s10956-017-9700-6

Cook, C., Goodman, N. D., \& Schulz, L. E. (2011). Where science starts: Spontaneous experiments in preschoolers' exploratory play. Cognition, 120(3), 341-349. doi:10.1016/j. cognition.2011.03.003

Dean, D., \& Kuhn, D. (2007). Direct instruction vs. discovery: the long view. Science Education, 91(3), 384-397. doi:10.1002/sce.20194

Dörner, D. (1997). The logic of failure: Recognizing and avoiding error in complex situations. New York: Basic Books.

Dörner, D., \& Funke, J. (2017). Complex problem solving: What it is and what it is not. Frontiers in Psychology, 8(1153), 1-11. doi:10.3389/fpsyg.2017.01153

Fields, R. D. (2016). Learning when no one is watching. Scientific American Mind, 27(5), 57-63.

Ford, M. J. (2005). The game, the pieces, and the players: generative resources from alternative portrayals of experimentation. The Journal of the Learning Sciences, 14(4), 449-487. doi:10.1207/s15327809jls1404_1

Forman, G. (1986). Observations of young children solving problems with computers and robots. Journal of Research in Childhood Education, 1(2), 60-74. doi:10.1080/02568548609594908

Funke, J. (2014). Analysis of minimal complex systems and complex problem solving require different forms of causal cognition. Frontiers in Psychology, 5(739), 1-3. doi:10.3389/fpsyg.2014.00739

Gibson, J. J. (1979). The ecological approach to visual perception. Boston: Houghton Mifflin.

Gopnik, A. (2010). How babies think. Scientific American, 303, 76-81. doi:10.1038/scientificamerican0710-76

Gopnik, A. (2012). Scientific thinking in young children: theoretical advances, empirical research, and policy implications. Science, 337(6102), 1623-1627. doi:10.1126/science.1223416

Graesser, A., Kuo, B.-C., \& Liao, C.-H. (2017). Complex problem solving in assessments of collaborative problem solving. Journal of Intelligence, 5(2), 10. doi:10.3390/jintelligence5020010

Greiff, S., Molnár, G., Martin, R., Zimmermann, J., \& Csapy, B. (2018). Students' exploration strategies in computer-simulated complex problem environments: A latent class approach. Computers and Education, 126, 248-263. doi:10.1016/j.compedu.2018.07.013

Greiff, S., Niepel, C., Scherer, R., \& Martin, R. (2016). Understanding students' performance in a computer-based assessment of complex problem solving: An analysis of behavioral data from computer-generated log files. Computers in Human Behavior, 61, 36-46. doi:10.1016/j.chb.2016.02.095 
Henderson, B., \& Moore, S. G. (1980). Children's responses to objects differing in novelty in relation to level of curiosity and adult behavior. Child Development, 51(2), 457-465. doi:10.2307/1129279

Hutt, C., \& Bhavnani, R. (1972). Predictions from play. Nature, 237, 171-172. doi:10.1038/237171b0

Jirout, J., \& Klahr, D. (2012). Children's scientific curiosity: in search of an operational definition of an elusive concept. Developmental Review, 32(2), 125-160, doi:10.1016/j.dr.2012.04.002.

Keller, H. (1994). A developmental analysis of exploration styles. In H. Keller, K. Schneider, \& B. Henderson (Eds.), Curiosity and exploration (pp. 199-212). Berlin: Springer-Verlag. doi:10.1007/978-3-642-77132-3_11

Klahr, D., \& Dunbar, K. (1988). Dual search space during scientific reasoning. Cognitive Science, 12, 1-48. doi:10.1207/s15516709 $\operatorname{cog} 1201 \_1$

Klahr, D., Zimmerman, C., \& Jirout, J. (2011). Educational interventions to advance children's scientific thinking. Science, 333(6045), 971-975. doi:10.1126/science.1204528

Mishra, S., \& Iyer, S. (2015). An exploration of problem posing-based activities as an assessment tool and as an instructional strategy. Research and Practice in Technology Enhanced Learning, 10(5), 119. doi:10.1007/s41039-015-0006-0

OECD. (2013). PISA 2012 Assessment and analytical framework: mathematics, reading, science, problem solving and financial literacy. Paris: OECD Publishing. doi:10.1787/9789264190511-en

OECD. (2017). PISA 2015: Collaborative problem-solving framework. Paris: OECD Publishing. Retrieved from http://www.oecd.org/pisa/pisaproducts/Draft\%20PISA\%202015\%20Collaborative\%20Problem\%20Sol ving\%20Framework\%20.pdf

Poddiakov, A. (1992). Teaching preschoolers combinatory experimentation. Journal of Russian and East European Psychology, 30(5), 87-96. doi:10.2753/RPO1061-0405300587

Poddiakov, A. (2011). Didactic objects for development of young children's combinatorial experimentation and causal-experimental thought. International Journal of Early Years Education, 19(1), 6578. doi:10.1080/09669760.2011.571001

Poddiakov, A. (2012). Complex problem solving at PISA 2012 and PISA 2015: Interaction with complex reality. Obrazovatel'naya Politika, 6, 34-53. (in Russian).

Poddiakov, A. (2014). Complicology: study of developing, diagnosing and destructive difficulties. Moscow: HSE Publishing House. (in Russian)

Poddiakov, A. (2017). Exploratory and counter-exploratory objects: design of meta-affordances. The Russian Journal of Cognitive Science, 4(2-3), 49-59. Retrieved from http://www.cogjournal.ru/4/3/pdf/PoddiakovRJCS2017.pdf (in Russian)

Poddiakov, N. (1959). Conditions of transformations of executive actions into exploratory ones. Reports of Academy of Educational Sciences of RSFSR, 5, 85-88. (in Russian)

Poddiakov, N. (1960). Orientating activity of preschoolers when forming and automating practical actions ( $\mathrm{PhD}$ dissertation). Institute of Psychology of Academy of Educational Sciences of RSFSR, Moscow. (in Russian)

Poddiakov, N. (1977). The thinking of a preschool child. Moscow: Pedagogika. (in Russian)

Poddiakov, N. (2011). Searching, experimenting and the heuristic structure of a preschool child's experience. International Journal of Early Years Education, 19(1), 55-63. doi:10.1080/09669760.2011.571000

Poddiakov, N. (2012). Features of mental development and self-development in the preschool child. Journal of Russian and East European Psychology, 50(2), 54-63. doi:10.2753/RPO10610405500207 
Poddjakow, N. (1981). Die denkentwicklung beim vorschulkind. Berlin: Volk und Wissen Volkseigener Verlag. (in German)

Riegler, A. (1998). "The end of science": can we overcome cognitive limitations? Evolution and Cognition, 4(1), 37-50.

Schauble, L. (1990). Belief revision in children: the role of prior knowledge and strategies for generating evidence. Journal of Experimental Child Psychology, 49(1), 31-57. doi:10.1016/00220965(90)90048-D

Schauble, L., Klopfer, L. E., \& Raghavan, K. (1991). Students' transition from an engineering model to a science model of experimentation. The Journal of Research in Science Teaching, 28(9), 859-882. doi:10.1002/tea.3660280910

Schulz, L. E., \& Bonawitz, E. B. (2007). Serious fun: Preschoolers engage in more exploratory play when evidence is confounded. Developmental Psychology, 43(4), 1045-1050. doi:10.1037/00121649.43.4.1045

Snider, J., Plank, M., Lynch, G., Halgren, E., \& Poizner, H. (2013). Human cortical $\theta$ during free exploration encodes space and predicts subsequent memory. The Journal of Neuroscience, 33(38), 15056-15068. doi:10.1523/JNEUROSCI.0268-13.2013

Alexander N. Poddiakov - professor, Department of Psychology, Faculty of Social Sciences, National Research University Higher School of Economics; senior research fellow, Institute of psychology, Russian Academy of Sciences, D.Sc.

Research area: cognitive psychology, developmental psychology, educational psychology.

E-mail: apoddiakov@hse.ru

Nikolay N. Poddiakov - Full Member of the Russian Academy of Education, D.Sc.

Research area: cognitive psychology, developmental psychology, educational psychology.

\title{
Интерактивные исследовательские объекты: от лабораторных экспериментов к массовым практикам XXI в.
}

\author{
А.Н. Поддьяков ${ }^{\mathrm{a}, \mathrm{b}}$, Н.Н. Поддьяков \\ ${ }^{a}$ Национальный исследовательский университет «Высшая школа экономики», 101000, Россия, \\ Москва, ул. Мясницкая, д. 20 \\ ${ }^{\text {b}}$ ФГБУН Институт психологии РАН, 129366, Москва, ул. Ярославская, д. 13, к. 1
}

\section{Резюме}

В статье обсуждаются истории и современные методы создания и применения интерактивных исследовательских объектов и миров, которые способствуют проявлению любознательности у человека, при этом для их освоения и достижения практических результатов требуются исследования и эксперименты. Разработка, использование и демонстрация разнообразных исследовательских объектов (игровых, образовательных, психодиагностических и др.) в различных сферах жизни отражают все более распространенное представление о том, что одна из основных способностей человека, которая необходима сегодня и ока- 
жется востребованной в будущем, - это способность совладания с новизной, в том числе посредством активных исследований и экспериментов. Определены пять взаимосвязанных направлений развития и популяризации исследовательских объектов: наука, образование, инструменты оценивания, игровые практики, а также литература, искусство, официальная и неофициальная журналистика. Обсуждаются особенности специально разработанных интерактивных исследовательских объектов и миров в контексте подготовки к столкновению с новизной и сложностью. Представлен треугольник тестов интеллекта, креативности и исследовательского поведения в пространстве «регламентированность - свобода». Описаны два типа мотивационных проблем, возникающих при исследовании новых объектов: исследование ради самого процесса познания и исследование ради желаемых практических результатов. Возникает вопрос об особенностях исследовательских объектов, стимулирующих постановку и решение эпистемических, а не прагматических задач, и наоборот. В заключении сформулированы возможные причины массового развития и реализации исследовательских объектов и миров.

Ключевые слова: интерактивные исследовательские объекты, экспериментирование, исследовательское поведение, интеллект, креативность, образование, игры.

Поддьяков Александр Николаевич - профессор, департамент психологии, факультет социальных наук, Национальный исследовательский университет «Высшая школа экономики»; главный научный сотрудник, Институт психологии Российской академии наук, доктор психологических наук, профессор.

Сфера научных интересов: когнитивная психология, психология развития, психология образования.

Контакты: apoddiakov@hse.ru

Поддьяков Николай Николаевич - действительный член Российской академии образования, доктор психологических наук, профессор.

Сфера научных интересов: когнитивная психология, психология развития, психология образования. 